\title{
Combating antibiotic resistance: New drugs or alternative therapies?
}

\author{
— Cite as: CMAJ 2017 September 18;189:E1199. doi: 10.1503/cmaj.109-5469
}

Posted on cmajnews.com on Aug. 29, 2017.

onversation about antibiotic resistance has been sparked again following a call by the World Health Organization (WHO) for new drugs to treat strains of gonorrhea resistant to available antibiotics.

An estimated 700000 people die annually from infection with drug-resistant microbes, a figure that is projected to increase to about 10 million by 2050. Last year the United Nations declared antimicrobial resistance to be one of the biggest threats to global health. While there's no disagreement that action must be taken to combat the evolving drugresistance crisis, just how to proceed remains a matter of debate.

For some, the logical step forward is to develop new antibiotics. Earlier this year, a team of researchers at the University of Manitoba discovered a drug that could be used to treat many infectious organisms, including gonorrhea. The drug targets a sodium pump that functions in certain metabolic processes in pathogenic bacteria.

"The target of [the antibiotic] is novel ... we are attacking a completely different aspect of bacterial viability," said Grant Pierce, one of the researchers and the executive director of research at St. Boniface Hospital in Winnipeg.

Despite the potential of developing new antibiotics, it is likely that microbes will eventually become resistant to them as well. According to Pierce, however, this shouldn't discourage research in the field.

"There is no reason why we shouldn't test [new antibiotics] and use them, because bacteria are not resistant to them now, so it provides us nothing but good things," he said.

Others, pointing out that new antibiotics will likely lead to more resistance, have called for innovation. That's why Bob Hancock, professor of microbiology

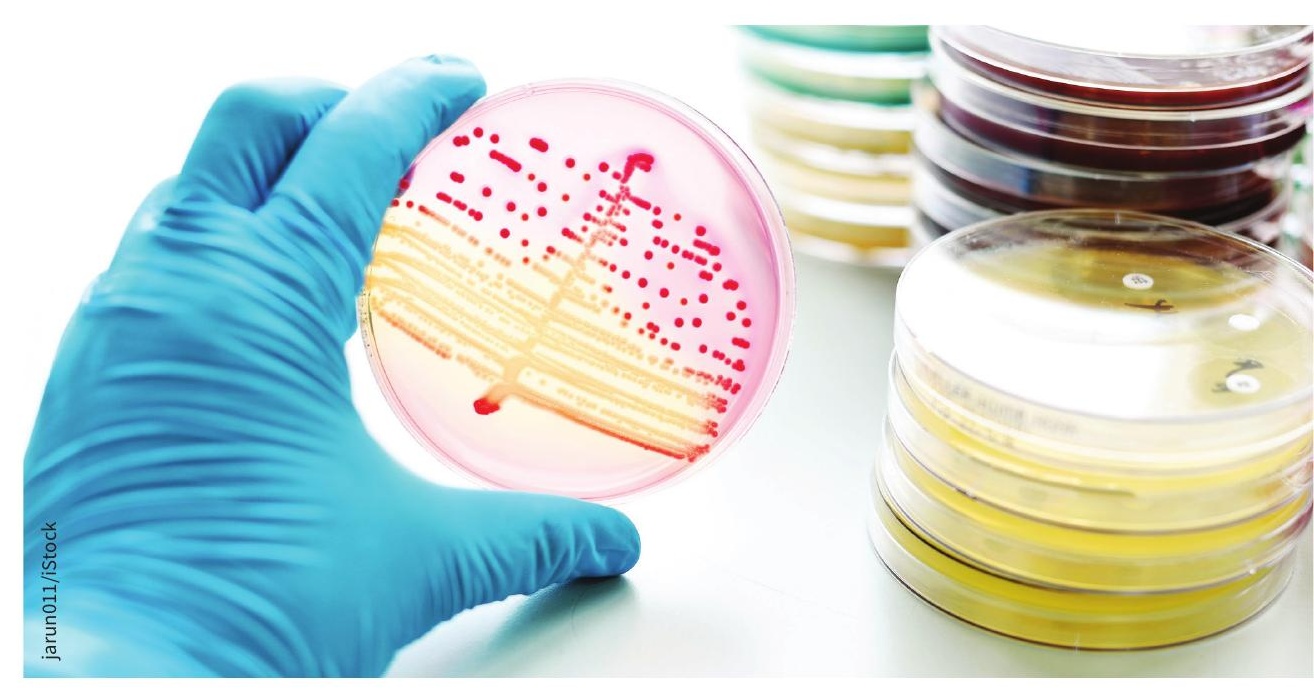

WHO calls for new drugs to treat antibiotic-resistant gonorrhea strains.

and immunology at the University of British Columbia, is developing solutions that aren't focused on new antibiotics.

"If we come up with new antibiotics, we're still going to have those same pressures for development of resistance," he said. "The drugs that we are producing today are just going to keep us in the game; they're not going to get us ahead of the game. In my opinion, we need to change the game."

Hancock is exploring the use of immune modulation therapy, hostdirected therapy, and probiotics as means of circumventing the problem of antibiotic resistance. Probiotics look particularly promising, he said. A 2014 study in Italy, for example, found a "considerable reduction of episodes of both streptococcal and viral infections" in children prone to developing the infection after they were given probiotics as a preventative measure.

Some of the solutions Hancock envisions could act as alternatives to antibiotics; others would be adjuncts that improve the effectiveness of existing antibiotics.
"I don't think we are abandoning anything. Instead, what we are doing is thinking of how we can take what we have right now and make it work better," he said.

Whether the solution to treating drug resistant pathogens such as gonorrhea ends up being new drugs or alternative therapies, clinical application of either is likely years away. In the meantime, it is critical to develop diagnostic tests that identify pathogens reliably and quickly, so that appropriate targeted drug therapy can be given right away, said Hancock. He also noted that limiting the use of antibiotics in food-producing animals is important to tackling antibiotic resistance.

As for which approach to combating antibiotic resistance will ultimately prevail, that is still up for debate. "Time will tell which [new solutions] are best," said Pierce. "My guess is that all of them will have varying degrees of success."

Vanessa Hrvatin, Vancouver, BC 